\title{
Telomerase RNA mutations in Saccharomyces cerevisiae alter telomerase action and reveal nonprocessivity in vivo and in vitro
}

\author{
John Prescott and Elizabeth H. Blackburn ${ }^{1}$ \\ Department of Microbiology and Immunology, University of California at San Francisco, \\ San Francisco, California 94143-0414 USA
}

\begin{abstract}
The ribonucleoprotein enzyme telomerase adds telomeric DNA to chromosomal ends. In most eukaryotes the telomeric repeat units are repeated precisely, consistent with the action of a telomerase that faithfully copies its RNA template. In contrast, Saccharomyces cerevisiae telomeric repeats are degenerate, suggesting that its telomerase has unusual mechanistic properties. We mutated the $S$. cerevisiae telomerase RNA (TLC1) with a series of 3-base (GUG) substitutions in and next to the 17-nucleotide templating domain. All mutant telomerases were active in TLC1/tIC1 diploids and synthesized patterns of mixed wild-type and mutant telomeric repeats into telomeric DNA, consistent with nonprocessive action. Telomerase isolated from cells containing each mutated $t \mid c 1$ allele by itself had altered reaction properties in vitro. One mutant template enzyme, 476GUG, was active in vivo and in vitro in the presence of wild-type TLC1 RNA but lacked detectable activity in its absence. Haploid tIc1-476GUG cells containing only this mutant tlc1 allele underwent senescence. Other tlc1 template region mutations allowed maintenance of shortened telomeres in vivo but altered specific enzymatic properties of telomerase in vitro, including induction of primer-template slippage (472GUG) or alteration of the $5^{\prime}$ boundary of the template (467GUG). These data demonstrate that telomerase RNA bases influence enzyme activity profoundly, suggesting that their roles are not confined to serving simply as the template for this specialized reverse transcriptase.
\end{abstract}

[Key Words: telomerase; S. cerevisiae; nonprocessivity; telomerase RNA]

Received November 4, 1996; revised version accepted January 10, 1997.

Telomeres, the specialized structures at the ends of all eukaryotic chromosomes, have a variety of functions. They cap the chromosome ends, protecting them from end-to-end fusion and degradation by nucleases and are required for chromosome stability (for review, see Blackburn 1994; Zakian 1995). Telomeres may also be involved in positioning chromosomes within the nucleus during interphase, where they appear to be clustered at or near the nuclear periphery (for review, see Dernburg et al. 1995). In premeiotic cells, telomeres may be involved in nuclear movements and have been proposed to play a role in homologous pairing during premeiosis (Chikashige et al. 1994; for review, see Kohli 1994).

Telomeres typically consist of short (6- to 8-nucleotide) tandem repeats, although some yeasts have homogeneous repeats of up to $26 \mathrm{bp}$ (McEachern and Blackburn 1994; Cohn and Blackburn 1995). Although the se-

${ }^{1}$ Corresponding author.

E-MAIL Porter@itsa.ucsf.edu; FAX (415) 465-8201. quence of the essential telomeric repeat unit is invariant in the majority of eukaryotes analyzed (e.g., TTGGGG in Tetrahymena and TTAGGG in vertebrates), it is notably degenerate in certain yeasts, the extreme being Saccharomyces cerevisiae, in which the telomeric repeat unit is $\mathrm{TG}_{2-3}(\mathrm{TG})_{1-6}$ (abbreviated $\mathrm{TG}_{1-3}$ ) (Shampay et al. 1984; McEachern and Blackburn 1994; Cohn and Blackburn 1995). Where analyzed, the extreme terminus of a telomere has been found to contain a $3^{\prime}$ single-stranded overhang during part, if not all, of the cell cycle (Klobutcher et al. 1981; Henderson and Blackburn 1989; Wellinger et al. 1993).

Conventional DNA polymerases are incapable of completely replicating the ends of a linear DNA molecule, and therefore of maintaining telomeric DNA (Watson 1972; Olovnikov 1973). Eukaryotes solve this end replication problem by replenishing their telomeric DNA using telomerase, a specialized ribonucleoprotein reverse transcriptase (for review, see Greider 1996). A short sequence in the telomerase RNA serves as a template for the synthesis of one strand of the telomeric repeat (Grei- 
TLC1 RNA mutations alter telomerase action

der and Blackburn 1989; Yu et al. 1990). Telomerase RNAs have been cloned from numerous ciliated protozoa, mouse, human, and the budding yeasts Kluyveromyces lactis and S. cerevisiae (Romero and Blackburn 1991; Lingner et al. 1994; Singer and Gottschling 1994; Blasco et al. 1995b; Feng et al. 1995; McEachern and Blackburn 1995). Mutations made in the templating domain of telomerase RNAs have been shown to appear in telomeric DNA synthesized in vivo in Tetrahymena thermophila, K. lactis, S. cerevisiae, and in vitro in $T$. thermophila, mouse, and human extracts, confirming the conserved templating role of telomerase RNA / Yu et al. 1990; Singer and Gottschling 1994; Autexier and Greider 1995; Blasco et al. 1995a; Feng et al. 1995; Gilley et al. 1995; McEachern and Blackburn 1995).

The RNA subunit of $S$. cerevisiae telomerase, encoded by the TLC1 gene, is a 1.3-kb RNA containing the 17base sequence $3^{\prime}$-ACACACACCCACACCAC-5' (Singer and Gottschling 1994). This portion of the RNA has been shown to include the template for telomere synthesis in vivo, as a pair of point mutations creating a HaeIII restriction site in this sequence of the TLCl gene caused the predicted HaeIII sites to appear in S. cerevisiae telomeres (Singer and Gottschling 1994). A TLC1 gene deletion is sufficient to cause telomere shortening and cellular senescence (Singer and Gottschling 1994), suggesting that as in other eukaryotes studied, there is only one telomerase RNA gene in S. cerevisiae. In addition, TLC1dependent telomerase activity has been found in $S$. cerevisiae by in vitro assays (Cohn and Blackburn 1995). This in vitro activity was limited to the addition of only a few nucleotides. In contrast, telomerase activity from the related Saccharomyces castellii was processive under similar conditions in vitro, adding multiple telomeric repeats to a single primer substrate molecule (Cohn and Blackburn 1995). The budding yeast K. lactis also has a long (30-base) templating domain in its 1.3-kb telomerase RNA, but in contrast to $S$. cerevisiae it synthesizes perfect 25-bp telomeric repeats in vivo (McEachern and Blackburn 1995). Hence, the irregularity of the $S$. cerevisiae repeats is not simply a consequence of a long template domain. Instead, it was proposed that S. cerevisiae telomerase stalls frequently, leading to premature dissociation of the elongating telomerase from its DNA substrate (Singer and Gottschling 1994; Cohn and Blackburn 1995).

Here we provide evidence for a mechanistic basis for the synthesis of degenerate telomeric repeats by the single $S$. cerevisiae telomerase enzyme. We show that five different mutant telomerases, with telomerase RNA mutations in or next to the template region, are active in vivo in the presence of wild-type telomerase. Results presented here suggest that telomerase acts nonprocessively in vivo. We confirm that telomerase in vitro is ATP-independent and largely nonprocessive, and further define the templating residues of the TLCl RNA. Strikingly, mutations in and adjacent to the templating domain cause unpredicted alterations in enzymatic activity, implicating base-specific interactions of this RNA in mediating crucial aspects of telomerase activity.

\section{Results}

In vivo activity of telomerases containing mutated TLC1 RNAs

To characterize the enzymatic action of telomerase in $S$. cerevisiae, we marked the telomerase RNA with a series of GUG substitutions, four within the maximum possible putative templating domain of the TLC1 gene and one immediately adjacent to it (Fig. 1A). Each mutation created an ApaLI restriction enzyme site. Five isogenic diploid strains were constructed, each containing one wild-type TLC1 gene and one $t 1 c 1$ mutant template gene (see Materials and Methods). Each TLC1/tlc1 strain grew similarly to wild type. Initial Southern blotting analyses showed no indication of ApaLI sites in the telomeres, even after $>80$ generations of growth (J. Prescott and E.H. Blackburn, unpubl.). This failure to detect ApaLI sites at telomeres suggested three possibilities: (1) The mutant telomerases functioned poorly or were inactive; $(2)$ the mutant enzymes were "sloppy" (i.e., unable to copy the full 6-base ApaLI site); or (3) the incorporation of telomeric DNA by the mutant enzyme was restricted to the extreme distal end of the telomere, making it difficult to visualize ApaLI cleavage by Southern analysis.

To differentiate between these possibilities, we used a plasmid rescue assay to examine telomeres created de novo in the presence of both wild-type and mutant telomerases. Previous work has shown that a HaeIII site introduced into the TLC1 gene template region can be transferred to a telomere extended in vivo from a seed sequence (Singer and Gottschling 1994). We transformed the TLC1/tlc1 diploid strains with a linearized plasmid containing terminal telomere seed sequences and selected cells that had maintained the plasmid (Fig. 1B). Maintenance of a linear plasmid is dependent on the ability of the cell to "heal" the exposed ends by telomere addition, a process stimulated by GT/CA-rich telomere seed sequences (Szostak and Blackburn 1982; Shampay et al. 1984; Lustig 1992). These linear plasmids containing telomeres added de novo were rescued from yeast transformants by recircularization and amplification in Escherichia coli, screened for the presence of an ApaLI site, and the telomeres added de novo were sequenced. For each tlc1-GUG template mutation, corresponding base changes were found in the sequences of the newly added telomeric DNA (Fig. 1C). Hence, the mutant telomerases were functional in vivo, and at least 11 residues (480-470) of the TLC1 RNA can act as templating residues. The mutant enzymes were not especially sloppy, as in 29 of 31 cases where mutant nucleotides were incorporated, an entire ApaLI site was present. Although most of the telomeres prescreened for an ApaLI site contained more than one mutant repeat, the repeats were not present as long stretches (Fig. 1C). Instead, sequences matching short stretches of the mutated template occurred most often either singly or in pairs (overlined sequences in Fig. 1C). The simplest explanation for this data is that the mutant enzymes acted nonprocessively in vivo. The separation of some mutant repeats by single wild-type repeats suggested that wild-type telom- 


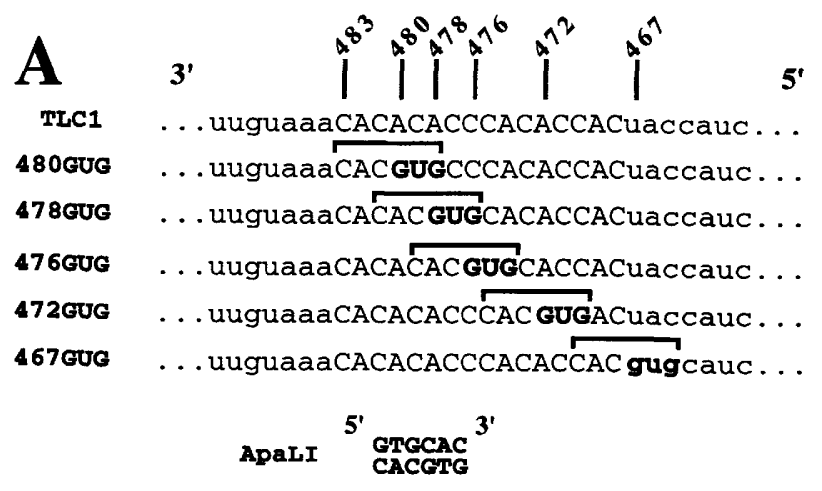

C

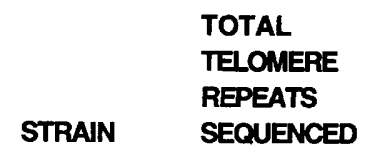

TrC1

tlc1-480GUG

60

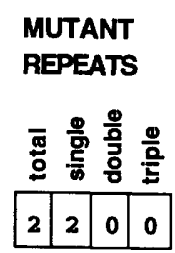

TrC1

tIc1-478GUG

89

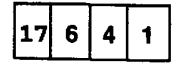

TrC1

t1c1-476GUG

18

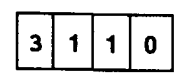

46

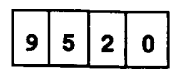

$\frac{\text { TrC1 }}{\text { t1c1-472GUG }}$

TLC1

tIc1-467GUG

100
B
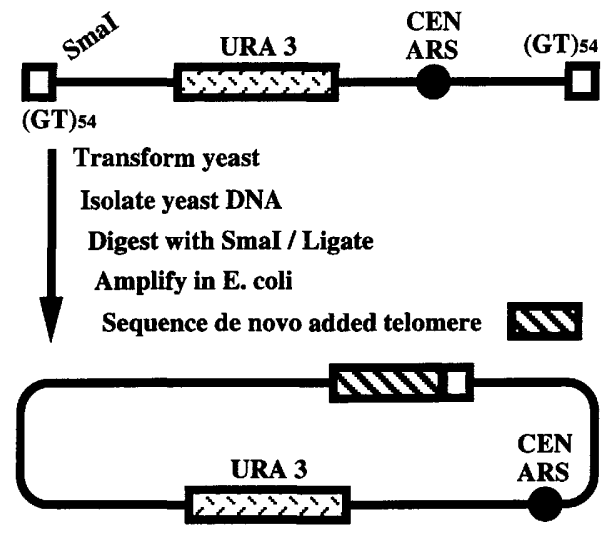

EXAMPLE MUTANT SEQUENCES

TGGTGTGGTGTGTGCACGGGTGTGTGTGTGTGTGGTTTGG GGTGTGTGGGTGTGCACG

GGGTGTGGTGT GTGTGCACGTGTGGTGTGTGGGTGTGGG

GTGGTGTGTGGETGTGCGTGTGGTGTGGGTGTGT

GTGGGTGTGGTGTGTGCACGTGTGGTGTGTGCACGGTGTGTGGG

GTGTGGGTGTGGTGTGCACGTGTGCACGTGTGGGTGTGTGTGTG

GTGTGGTGTGCGTGTGCACGTGTGCACGTGTGGTGTGTGTGGG

GGGTGTGGTGTGTGTGTGCACGTGTGTGCACGTGGTGTGTGGG

GTGTGGGTGTGGTGTGCACGTGGTGTGTGTGGG

TGTGTGGGTGTGTGGGTGCACTGTGGGTGTTGGGTGTGT

TGGTGTGTGGGTGTGGGTGCACTGTGTGTGGGTGTGGTGTG

TGTGGTGTGTGTGGGTGCACTGTGTGGGTGTGGTGT

TGTGTGTGTGGGTCACTGTGTGTGGGTGCACTGTGTGTGT

GGGTGCACTGGTGCACTGTGGGTGTGGGTGCACTGTGGTGTGGGTGCACTGTGGG

Figure 1. Mutant template telomerases are functional in vivo. (A) Partial sequence of the TLC1 RNA in wild-type and template mutation strains. Uppercase letters indicate the proposed templating domain; bold nucleotides (GUG) indicate mutated residues. Brackets mark ApaLI sites. $(B)$ Cloning of de novo telomeres. ( $\square$ ) Telomere seed sequences consisting of $108 \mathrm{bp}$ of $(\mathrm{GT} / \mathrm{CA})$, oriented with the GT strand extending from 5' to $3^{\prime}$ toward the plasmid end. $(C)$ Sequences of telomeres created de novo in TLC1/tlc1 template mutation strains. Total telomere repeats sequenced is based on an assumed average repeat length of 14 nucleotides. Mutant repeats indicate the number of repeats containing complementarity to the mutant template tlcl RNA, along with the number of mutant repeats present as single, and uninterrupted double and triple repeats. Bars over the sequences indicate regions of complementarity with the tlcl mutant templating domain.

erase is similarly nonprocessive. However, we cannot rule out the possibility that the telomeric sequences shown in Figure 1C are the result of processive elongation by telomerase, with successive bursts of elongation separated by degradation of newly added telomeric DNA. Such degradation could by catalyzed by a specific nuclease, or even by a cleavage activity intrinsic to wild-type telomerase. In each TLC1/tlc1 diploid, the mutant repeats were underrepresented in the telomeres added de novo, suggesting either reduced enzymatic activity of the template mutant enzymes and/or selective loss of the mutant repeats in vivo.
To determine whether each mutant telomerase could support telomere maintenance on its own, diploid TLC1/tlc1 strains were sporulated. The growth characteristics and length distribution of the terminal telomeric $\mathrm{TG}_{1-3}$ repeat tracts were examined in each haploid tlc1 strain. Four of the five mutant strains grew similarly to wild type over four restreaks (85 cell doublings) (Fig. 2A,B; tlc1-467GUG, tlc1-472GUG, tlc1-478GUG, and tlc1-480GUG). However, each of these tlc1 mutations caused significant telomere shortening, as measured by telomeric restriction fragment lengths (Fig. $2 \mathrm{C}$ and D, cf. the lower broad bands in odd-numbered lanes with ar- 
A

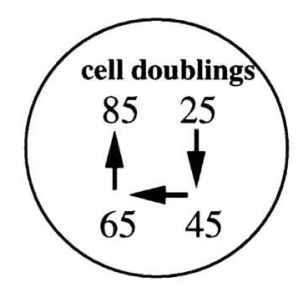

B
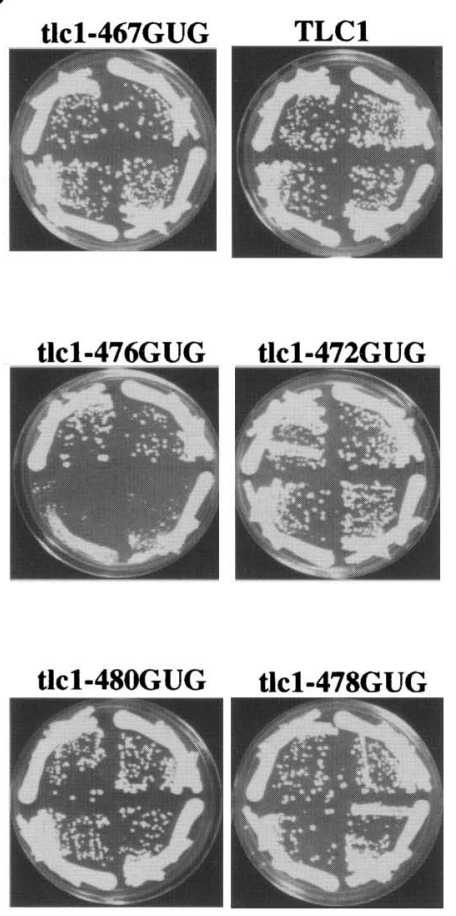

C

D
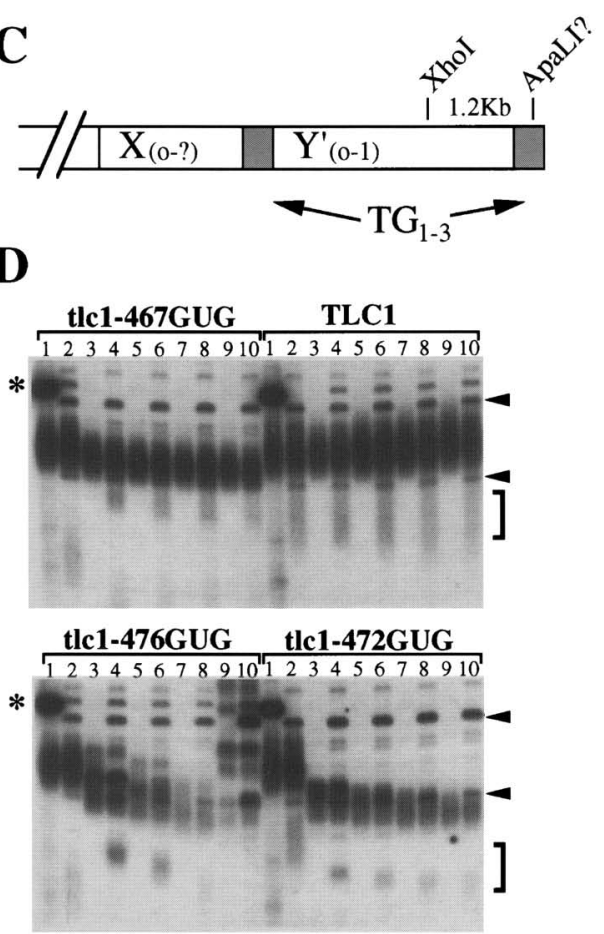

tlc1-480GUG tlc1-478GUG

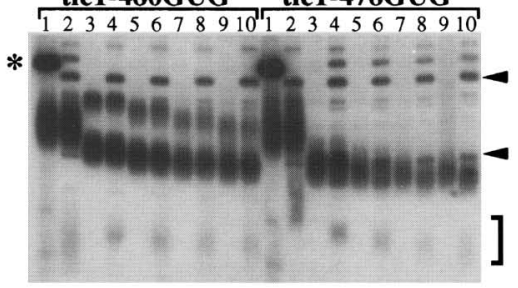

Figure 2. Telomeres are maintained at shortened lengths by the mutant template telomerases. (A) Guide to $B$, containing haploid template mutant strains plated 25 , 45,65 , and 85 generations following sporulation of TLC1/tlc1-template mutant diploids. $(C)$ A typical yeast telomere. The XhoI site is conserved in the majority of yeast telomeres ( $\mathrm{Y}^{\prime}$ class), $\sim 1.2 \mathrm{~kb}$ from the terminus. (D) Southern blot analysis of terminal XhoI restriction fragments in haploid mutant template strains. Genomic DNAs prepared from haploid wild-type (lanes 1,2 ) or mutant template strains prepared 25 (lanes 3,4), 45 (lanes 5,6), 65 (lanes 7,8 ), and 85 (lanes 9,10) generations after sporulation were digested with either $X h o I$ (odd-numbered lanes) or XhoI and ApaLI (even-numbered lanes), separated on a $0.8 \%$ agarose gel, and probed with an $\alpha-{ }^{32}$ P-labeled (TGTGGG) ${ }_{4}$ oligonucleotide probe. Arrowheads indicate internal crosshybridizing fragments. Asterisks (lanes 1) indicate cross-hybridization to the $1.6-\mathrm{kb}$ fragment of a 1-kb DNA ladder, run in the same lane as all XhoI-cut TLC1 DNAs. Brackets indicate hybridization to a telomere lacking a $\mathrm{Y}^{\prime}$ repeat. rows marking internal $\mathrm{TG}_{1-3}$ tracts). Of these four strains, mutations within the template $(t 1 c 1-472 G U G$, tlc1-478GUG, and t1c1-480GUG) caused the most severe loss ( $>200 \mathrm{bp}$ ) of terminal sequence.

The remaining haploid mutant template strain $|t| c 1-$ $476 G U G$ ) was unable to maintain telomeres, causing the strain to senesce (Fig. 2B) and telomeres to first shorten and then undergo rearrangements (Fig. 2D). Similar telomeric rearrangements have been seen in strains lacking a functional EST1 gene, which is required for telomere maintenance in vivo (Lundblad and Szostak 1989; Lundblad and Blackburn 1993). Interestingly, in tlc1476GUG cells the onset of senescence occurred when their telomeres were longer than those in late-passage t1c1-472GUG and tlc1-478GUG cells, which grew comparably to wild type with no signs of senescence (Fig. 2D, cf. the strongest broad telomeric band in lanes 5 and 6 of t1c1-476GUG with that in lanes 9 and 10 of t1c1$472 G U G$ and $t 1 c 1-478 G U G)$.

Like the TLC1/tIC1 template mutation diploids, none of the haploid tIc1 mutant strains incorporated ApaLI sites efficiently into the chromosomal telomeres (Fig. $2 \mathrm{D}$, cf. the strong broad telomeric band in lanes $3,5,7$, and 9 with that in lanes $4,6,8$, and 10 , respectively).
These data suggest that when the mutant telomerase acts on originally full-length endogenous chromosomal telomeres, any mutant repeats are restricted to the extreme terminus of the $\mathrm{TG}_{1-3}$ tract. This differs from the de novo synthesis of telomeres in the TLC1/tlc1 diploids, in which mutant repeats were interspersed throughout the added telomere (Fig. 1C). Together, these results, as well as the underrepresentation of mutant repeats in de novo telomeres in diploid strains, suggested that the enzymatic activity of the t1c1 mutant enzymes was reduced.

Both the 476GUG and the 478GUG mutant telomerases created telomeric sequences that altered the consensus binding site for Raplp at conserved positions /cf. telomere sequences in Fig. 1C to the Raplp concensus binding site in Fig. 3A). As predicted, in both instances Raplp binding to these two altered telomeric repeats in vitro was reduced $>3000$-fold compared to the wild-type sequence, as measured by gel shift experiments (Fig. 3B). Thus, reduced Raplp binding at telomeres is unlikely by itself to be the cause of senescence of the tIc1-476GUG strain, as the t1c1-478GUG mutant grew similarly to wild type. Reduced Raplp binding of telomeric DNA has been found to cause telomere lengthening, rather than 
A
Concensus
$\begin{array}{lllllllllllll}R & R & T & G & N & N & T & G & G & G & T & Y \\ \mathbf{Y} & Y & \mathbf{A} & \mathbf{C} & \mathbf{N} & \mathbf{N} & \mathbf{A} & \mathbf{C} & \mathbf{C} & \mathbf{C} & \mathbf{A} & \mathbf{R}\end{array}$
WT
T G T G G T G T G T G G G T G T G G T G T
476
$\begin{array}{lllllllllllllllllllll}A & C & A & C & C & A & C & A & C & A & C & C & C & A & C & A & C & C & A & C & A\end{array}$
T G T G G T G T G T G C a C
$\begin{array}{lllllllllllllllllllll}A & C & A & C & C & A & C & A & C & A & C & g & t & g & C & A & C & C & A & C & A\end{array}$

Figure 3. The 476CAC and 478CAC muta-

tions prevent Rap1p binding. $(A)$ Concensus Raplp binding site, along with the doublestranded oligonucleotide substrates used for in vitro binding assays. $(B) \mathrm{Gel}$ shift assays with (lanes 2-10) or without (lane 1) S-100 whole-cell extracts and ${ }^{32} \mathrm{P}$-labeled doublestranded wild-type (WT) oligonucleotides. The indicated unlabeled double-stranded competitor oligonucleotides were included at 1-, 3-, 10-, 30-, 100-, 300-, 1000-, and 3000 -fold (lanes 3-10, respectively) molar excess over the labeled wild-type oligonucleotides. Arrow indicates Raplp-bound wild-type substrate oligonucleotides.
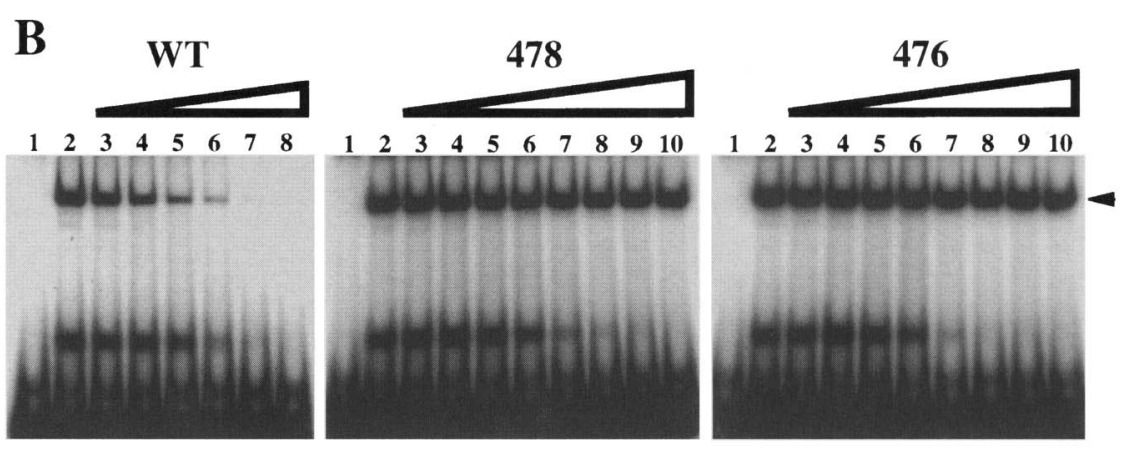

shortening, in $K$. lactis strains with telomerase RNA template mutations (McEachern and Blackburn 1995; Krauskopf and Blackburn 1996). Therefore, we analyzed telomerase activity in the haploid $t l c 1$ strains directly in vitro.

\section{In vitro activity of mutant telomerases}

We compared in vitro telomerase activity from wild-type and the various tlc1 mutant haploid cells. In these in vitro assays, a variety of single-stranded DNA oligonucleotide primers were extended by telomerase in the presence of $\left[\alpha{ }^{-32} \mathrm{P}\right] \mathrm{dTTP}$ and unlabeled dGTP (or ddGTP), dATP, and dCTP. Telomerase reaction products were initially identified by their sensitivity to RNase pretreatment of the enzyme and to chain termination by ddGTP at a predicted position in the templated elongation reaction. The primers used are shown optimally aligned by base-pairing with the wild-type RNA template in Figure $4 \mathrm{~A}$. The $3^{\prime}$ terminus of these primers is predicted to anneal to position 475 of the template RNA. Thus, if synthesis proceeds to the $5^{\prime}$ end of the maximum possible template (position $468 \mathrm{C}$ ), up to 7 nucleotides will be added in a single round of extension (see Fig. 4A). Primers containing compensatory changes to restore complementarity with the mutated template bases were used for the 476GUG, 478GUG, and 480GUG mutant enzymes (Fig. 4A).

The four mutant telomerases (467GUG, 472GUG, 478GUG, and 480GUG) that supported normal cell growth in haploids were active in vitro, and each catalyzed a single round of extension (Fig. 4B, lanes $6,9,15,18)$. In contrast, the 476 GUG telomerase was reproducibly inactive in vitro when isolated from haploid t1c1-476GUG mutant cells (Fig. 4B, lane 12). Further characterization of this telomerase is described below. As shown previously with wild-type telomerase /Cohn and Blackburn 1995), preincubating each of the four mutant enzymes with RNase A prevented polymerization (lanes $1,4,7,13,16)$. In the presence of ddGTP, polymerization stopped after the addition of two nucleotides (lanes 2,5,8,14,17), as predicted for TLC1 RNA-templated addition. However, although all reactions contained equal amounts of telomerase RNA, these four mutant tlcl telomerases were slightly less active than the wild type (Fig. 4B, cf. reaction products in lanes 6, 9, 15 , and 18 to that in lane 3 ), suggesting that these mutant enzymes were reduced in either intrinsic enzymatic activity and/or the assembly of tlcl RNA into a functional enzyme. This reduction may have contributed to the underrepresentation of mutant repeats seen in TLC1/tIc1 heterozygous diploids and the shorter chromosomal telomeres in these four haploid mutant strains.

Telomerase reactions were limited to a single round of extension. Thus, this enzyme was nonprocessive in vitro, in that it did not undergo repeated rounds of translocation to the $3^{\prime}$ end of the template followed by polymerization. This was also observed in the presence of increased concentrations of $\mathrm{NaOAc}$ (Fig. 4C, lanes 1-3), dTTP (Fig. 4C, lanes 4-6 and 10-12) or $\mathrm{MgCl}_{2}$ (Fig. 4C, lanes 7-9). In addition, fractionation on a cation exchange column or a heparin column resulted in telomerase activity that was indistinguishable from the DEAE-agarose-fractionated enzyme (Fig. 4E, lanes 1,2; data not shown). An RNase sensitive, TLC1-dependent in vitro activity has been described in $S$. cerevisiae, which was more processive than the telomerase activity assayed here, and whose processivity was enhanced by ATP (Lue and Wang 1995). Therefore, we tested the effect of ATP and the nonhydrolyzable analogs AMPPNP 
A

\section{Primer Primer/Template Annealing}

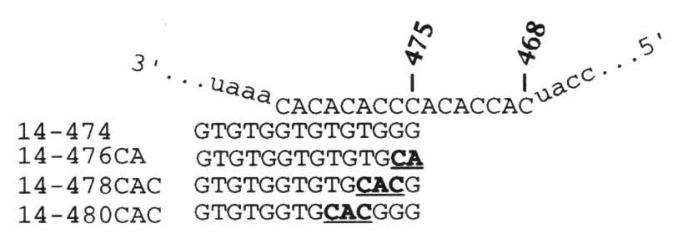

B
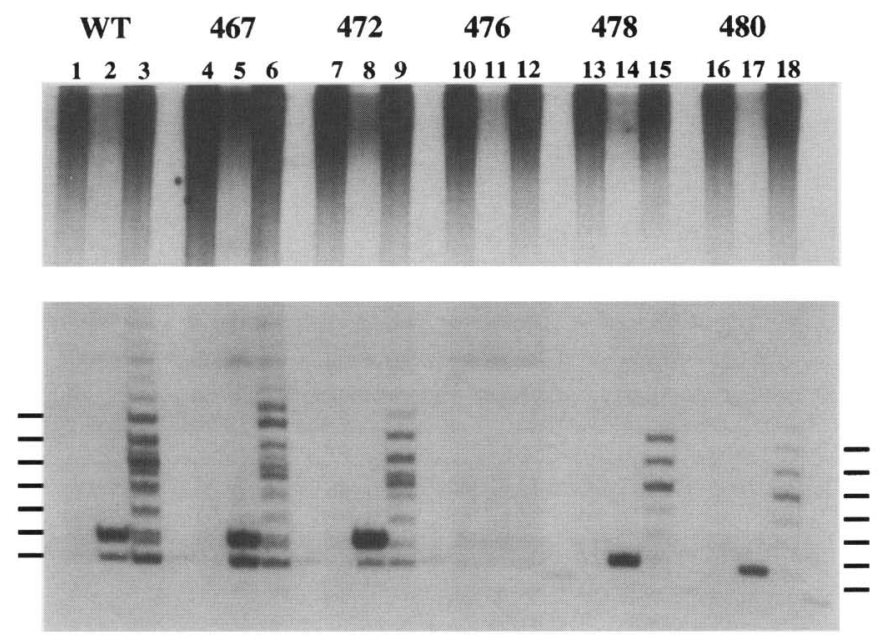

Figure 4. In vitro telomerase activity isolated from haploid $t l c 1$ mutant template strains. $(A)$ Predicted alignment of primers with the template domain of the TLC1 RNA. Bold underlined nucleotides indicate nontelomeric primer residues that restore primer complementarity with the mutant template telomerases. Numbers above the TLC1 RNA refer to the distance from the $5^{\prime}$ end of the reported TLC1 sequence. (B) Telomerase-containing fractions prepared from the indicated haploid $t 1 c 1$ mutant template strains were incubated with primer 14-474 (lanes 1-9), 14-476CA (lanes 10-12), 14-478CAC (lanes 13-15), or 14-480CAC (lanes 16-18) under standard reaction conditions containing all four dNTPs (lanes 1,3-4,6-7,9-10,12-13,15-16,18) or with ddGTP substituted for dGTP (lanes 2,5,8,11,14, and 17). In control reactions, extracts were preincubated with RNase A (lanes 1,4,7,10,13,16). The unlabeled lanes to the right of lanes $3,6,9,12,15$, and 18 contain 3 -labeled (TdT and $\left.\left[-\alpha^{32} \mathrm{P}\right] \mathrm{dTTP}\right)$ primer +1 markers. Reaction products were separated on a $15 \%$ acrylamide $/ 8 \mathrm{M}$ urea gel. Markers indicating the size of the seven major reaction products are indicated at the sides of the gel. The central portion of the gel is not shown. $(C)$ Wild-type telomerase-containing fractions were incubated with primer 14-474 under standard reaction conditions (lanes 1,4,7,10), with $0.3 \mathrm{M}$ and $0.6 \mathrm{M} \mathrm{NaOAc}$ (lanes 2,3), 57.5 and $107.5 \mu \mathrm{M}$ dTTP (lanes 5,6; lanes 11,12), or 5 and $10 \mathrm{mM} \mathrm{MgCl}_{2}$ (lanes 8,9). Lanes 10-12 are identical to lanes 4-6, but were exposed to film five times longer. (D) Wild-type telomerasecontaining fractions were incubated with primer 14-474 (lane 1) in the presence of $1 \mathrm{mM} \mathrm{ATP,} \mathrm{AMPPNP,} \mathrm{or} \mathrm{ATP} \gamma \mathrm{S}$ (lanes 2-4), and reaction products were separated on a $15 \%$ acrylamide $/ 8 \mathrm{M}$ urea gel. (E) Wild-type S-100 fraction was fractionated on an Econo-Pac S cartridge (Bio-Rad), and the flowthrough was assayed for telomerase activity under standard conditions (lane 1), following RNase A pretreatment (lane 2), or with the addition of $1 \mathrm{mM}$ ATP (lane 3). The unmarked lane contains 3 ' - labeled primer as a +1 size marker.

and ATP $\gamma$ S on wild-type telomerase activity fractionated on DEAE-agarose or a cation exchange column. The products did not get longer when either ATP, AMPPNP, or ATP $\gamma$ S were present (Fig. 4 D, lanes 1-4, and E, lanes $1,3)$. The reduced processivity observed with enhanced polymerization stops after the addition of the second and fifth added nucleotides suggests that competition by the high concentration of ATP, AMPPNP, or ATP $\gamma$ S resulted in a pause before the incorporation of dTTP. Similar competition with $\left[\alpha{ }^{32} \mathrm{P}\right] \mathrm{dTTP}$ by high concentrations of dATP was reported with Tetrahymena telomerase (Greider and Blackburn 1985).
The t1c1-472GUG template mutation alters telomerase behavior in vitro

The 472GUG mutant telomerase was expected to add a mutant sequence (tgcactg) to the TGGG-ending primer used in the experiments shown in Figure 4B. To verify that this mutant telomerase added $\mathrm{dC}$ and $\mathrm{dA}$ residues, telomerase reactions were performed in the presence of ddCTP and ddATP. Polymerization by the 472GUG enzyme was blocked by both ddCTP and ddATP, whereas polymerization by the wild-type enzyme was not (Fig. $5 \mathrm{~B}$, cf. lane 5 with lane 10 and lane 6 with lane 11 ). 
Replacing $\mathrm{dG}$ or $\mathrm{T}$ residues with $\mathrm{dC}$ or $\mathrm{dA}$ residues in the primer or product causes product bands to migrate faster in the gel. Hence, in Figure 4B there is a downward shift in the ddG-terminated +2 products with primers 480CAC and 478CAC (cf. lanes 14 and 17 with lanes 2, 5 , and 8). The downward shift in the +5 doublet band generated by the 472GUG telomerase (Fig. 4B, cf. lane 9 with lanes 3 and 6) was also consistent with incorporation of cac into the reaction products. These results demonstrate clearly that the activity characterized here results from TLC1-templated reverse transcription by yeast telomerase.

A striking behavior was exhibited by the 472 GUG mutant enzyme in the presence of just dGTP and dTTP.
Although synthesis was expected to stop after the addition of 2 nucleotides, high levels of up to 15 nucleotides were added (Fig. 5B, lane 12), suggesting that a form of slippage synthesis was greatly enhanced in this mutated enzyme. In contrast, in a comparable situation in which the wild-type telomerase was deprived of dGTP, synthesis stopped as predicted after addition of a single $\left[{ }^{32} \mathrm{P}\right] \mathrm{dTTP}$ (Fig. 5B, lane 2).

\section{Primer-template mismatches promote slippage synthesis and primer cleavage}

The mutant template telomerases enabled specific questions about enzyme action to be addressed. Synthesis of
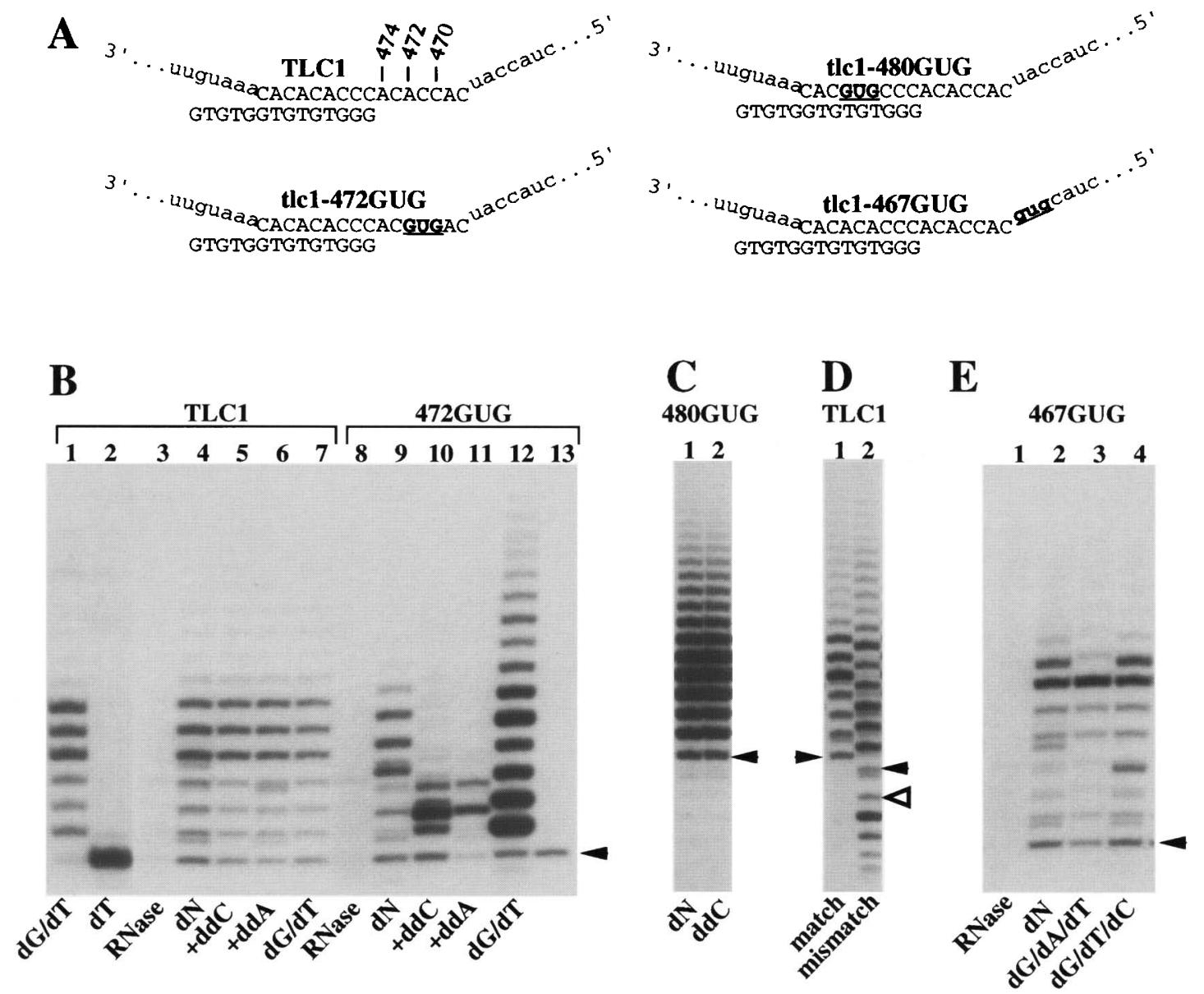

Figure 5. TLC1 template mutations affect polymerization characteristics. (A) Predicted alignment of primers with the template domain of the TLC1 (and mutant template tlc1) RNA. Bold underlined nucleotides indicate mutated tlc1 residues. $(B)$ Either wild-type or 472GUG telomerase fraction was incubated with primer 14-474 and all four dNTPs (lanes 3,4 and 8,9) or with the following nucleotide changes: dGTP and dTTP only (lane 1,7,12), dTTP only (lane 2), dCTP replaced with ddCTP (lanes 5,10), and dATP replaced with ddATP (lanes 6,11). In control reactions, extracts were preincubated with RNase A (lanes 3,8 ). Reaction products were separated on a $15 \%$ acrylamide $/ 8 \mathrm{M}$ urea gel. The arrowhead indicates terminal transferase-labeled $14-474$ as a +1 size marker (lane 13 ). $(C)$ 480GUG telomerase fraction was incubated with primer 14-474 and all four dNTPs (lane 1), or with dCTP replaced with ddCTP (lane 2). The arrowhead indicates primer +1 reaction product. $(D)$ Wild-type telomerase fraction was incubated with primer $14-474$ (lane 1 ) or primer 14-480CAC (lane 2) in the presence of all four dNTPs. The solid arrowheads indicate primer +1 reaction products; the open arrowhead indicates primer-sized product. (E) 467GUG telomerase fraction was incubated with primer 14-474 and all four dNTPs (lanes 1,2) or with only three dNTPs, lacking either dCTP (lane 3) or dATP (lane 4). A control reaction was preincubated with RNase A (lane 1). The arrowhead indicates primer +1 reaction product. 
long (>+7) products by the wild-type telomerase, reminiscent of those seen in the 472GUG dGTP/dTTP-only reaction, was minor but detectable (e.g., see Fig. 4, B, lane 3 , and $C$, lane 10). These products became more prominent when mismatched enzyme and primer pairs were used, as seen when the 480GUG template mutant telomerase was incubated with primer 14-474, creating a 3-nucleotide primer-template mismatch (Fig. 5, A, top right, and $C$, lane 1). To determine whether these longer products represented primer slippage or a second round of synthesis, the effect of ddCTP on this reaction was tested. In this reaction, ddCTP would cause chain termination only if the first-round products translocated back to the $3^{\prime}$ nucleotides of the telomerase RNA templating domain, followed by a second round of synthesis copying the mutated residues. However, ddCTP had no effect on the reaction product profile (Fig. 5C, cf. lanes 1 and 2). Hence, the long $(>+7)$ products apparently result from primer slippage within the eight $5^{\prime}$ bases of the template. Slippage synthesis, exacerbated by certain template mutations, has also been seen with Tetrahymena telomerase (Gilley et al. 1995; Gilley and Blackburn 1996; He Wang and E.H. Blackburn, unpubl.).

Incubating wild-type telomerase with the mismatched primer 14-480CAC generated a labeled, primer-sized product (Fig. 5D, open arrowhead) and four shorter labeled products, in addition to the standard seven elongation products (Fig. 5D, lane 2; the solid arrowhead marks the primer +1 product). Synthesis of these shorter products was stimulated by the primer-template mismatch (Fig. 5D, cf. lanes 1 and 2). They were not seen with matched wild-type template-primer reactions (Fig. $5 \mathrm{D}$, lane 1), or with 480GUG telomerase and the matched primer 14-480CAC (Fig. 4B, lane 18; data not shown). Labeled products the same length as, and shorter than, the input primer result from cleavage and subsequent extension of the shortened primer and have been described for Tetrahymena and Euplotes telomerases (Collins and Greider 1993; Melek et al. 1996). Together, these observations suggest that $S$. cerevisiae telomerase is able to remove mismatched residues before extending a primer.

The GUG mutation next to the templating domain alters the $5^{\prime}$ template boundary

The 467GUG telomerase efficiently synthesized a +8 product in vitro, in contrast to the wild-type and other mutant enzymes (Figs. 4B and 5E, lanes 6 and 2, respectively). Synthesis of this +8 product specifically required dCTP (Fig. 5E, cf. lanes 2 and 3), suggesting that the 467GUG base changes allow copying of the mutant $G$ at position 467 , one nucleotide beyond the normal template (see Fig. 5A). A similar effect on in vitro synthesis has been seen by alteration of the region $5^{\prime}$ of the templating domain in the Tetrahymena telomerase RNA (Autexier and Greider 1995). Although the sequences in Figure 1C showed no indication of $\mathrm{dC}$ incorporation by the 467GUG telomerase in vivo, we cannot eliminate the possibility that this enzyme incorporates $\mathrm{dC}$ resi- dues, which are cleaved off prior to subsequent rounds of telomere addition. Such a cleavage action would be consistent both with the mismatch-stimulated cleavage demonstrated in Figure 5D and with results obtained with Tetrahymena and Euplotes telomerases, which cleave 3 ' residues from their oligonucleotide substrates in the vicinity of the $5^{\prime}$ end of the template (Collins and Greider 1993; Melek et al. 1996).

\section{GUG telomerase from tlc1-476GUG haploids is inactive but is active when isolated from TLC1/tlc1-476GUG diploids}

Although the haploid t1c1-476GUG strain lacked telomerase activity (Fig. 4B), stable 476GUG telomerase RNA was present in these cells at levels comparable to wild type and apparently assembled into a normal telomerase RNP, as it fractionated similarly to wild-type TLC1 RNA/telomerase activity on a DEAE column and migrated similarly to wild-type TLCl RNA on a native gel (J. Prescott and E.H. Blackburn, unpubl.). This lack of activity was not attributable to poor cell growth, as these (and all other mutant) extracts were made from late-passage cells, by which time this strain had generated survivors that grew similarly to wild type. Survivors of an EST1 deletion have also been shown to have normal telomerase activity in vitro, suggesting that the survivor state per se does not inhibit telomerase catalytic activity (Cohn and Blackburn 1995). Furthermore, a contaminating polymerase activity, seen as RNase-insensitive incorporation of radiolabel in partially purified fractions from all strains, was active in three independantly prepared haploid tlc1-476GUG extracts (Fig. 4B, top; RNase-insensitive products at top of gel in lanes $1,4,7$, 10, 13, and 16; data not shown). Therefore, we propose that lack of telomerase activity caused the haploid tlc1476GUG strain to senescence.

In TLC1/tlc1-476GUG diploids, the 476GUG telomerase RNA template was copied in vivo (Fig. 1C), suggesting that this mutant telomerase requires the presence of wild-type telomerase RNA to function. To test this directly, extracts from TLC1/t1c1-476GUG heterozygous diploid cells were fractionated and assayed for telomerase activity, using a primer whose $3^{\prime}$ end was complementary to the mutant RNA template (Fig. 6A). To selectively assay copying of the mutant template, the label was $\left[\alpha-{ }^{32} \mathrm{P}\right] \mathrm{dCTP}$, as incorporation of $\mathrm{dC}$ residues can only be templated by the mutant telomerase. Incubation with all four dNTPs including $\left[\alpha-{ }^{32} \mathrm{P}\right] \mathrm{dCTP}$ gave the expected seven labeled reaction products (Fig. 6B, lane 1). Substituting dGTP and dTTP with ddGTP and ddTTP, respectively, resulted in +2 and +3 strong stop products, as predicted for templating by the 476GUG mutant RNA (Fig. 6B, lanes 2,3). As expected, substitution of DATP with ddATP had no effect on the product profile (Fig. 6B, lane 4). Therefore, under these conditions the 476GUG template was copied, indicating that the mutant telomerase was functional.

We also tested whether the haploid t1c1-476GUG cells contained an inhibitor of telomerase activity, by 

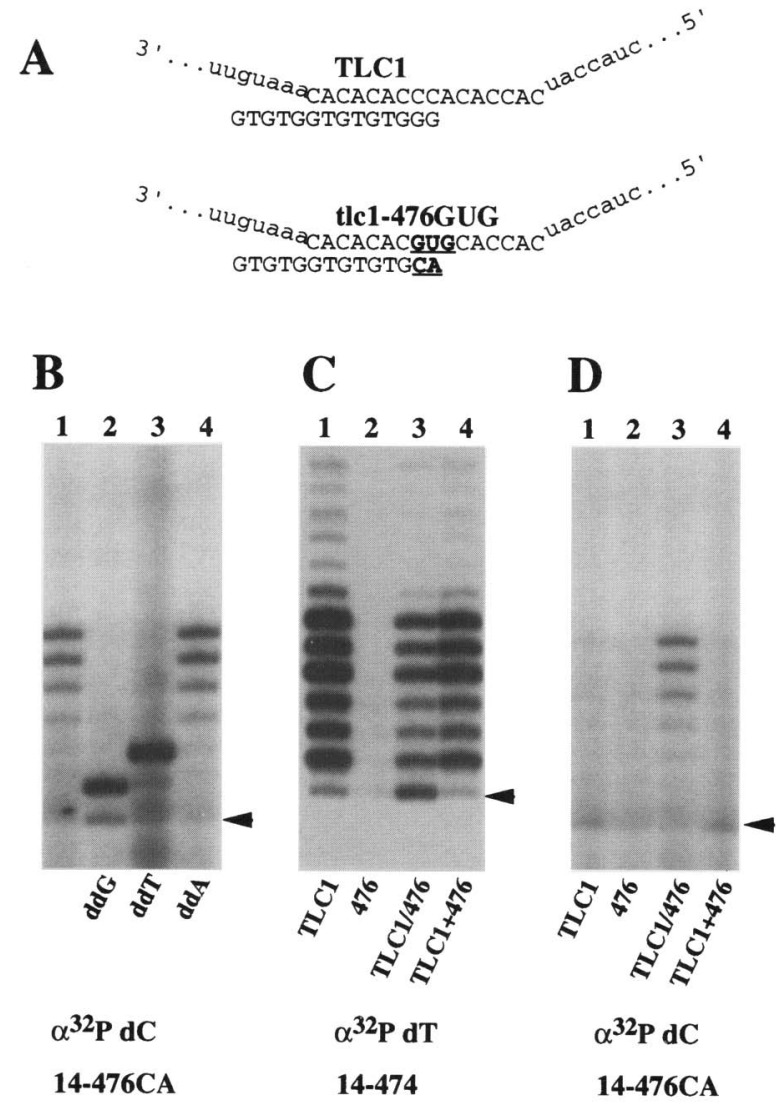

Figure 6. 476GUG template mutant telomerase is active when isolated from TLC1/tIC1-476GUG diploids. (A) Predicted alignment of primers with the template domain of wild-type and 476GUG telomerase RNA. Bold underlined nucleotides indicate mutated tlcl residues or compensatory alterations in primer sequence. $(B)$ Telomerase-containing fractions prepared from $T L C 1 / t$ IC1-476GUG diploids were incubated with primer 14-476CA, $\left[\alpha-{ }^{32} \mathrm{P}\right] \mathrm{dCTP},-\mathrm{dGTP},-\mathrm{dATP}$, and -dTTP (lane 1) or the following nucleotide substitutions: ddGTP for dGTP (lane 2), ddTTP for dTTP (lane 3), or ddATP for dATP (lane 4). Reaction products were separated on a $15 \%$ acrylamide $/ 8 \mathrm{M}$ urea gel. The arrowhead indicates primer +1 reaction product. $(C)$ Telomerase-containing fractions from wild-type (lane 1), tlc1476GUG haploids (lane 2), TLC1/t1c1-476GUG diploids (lane 3), or a mixture of TLC1 and tlc1-476GUG haploid fractions (lane 4) were incubated with primer 14-474, $\left[\alpha-{ }^{32} \mathrm{P}\right] \mathrm{dTTP}$, -dGTP, -dATP, and -dCTP. The arrowhead indicates primer +1 reaction product. $(D)$ The fractions described in $C$ were incubated with primer $14-476 \mathrm{CA},\left[\alpha-{ }^{32} \mathrm{P}\right] \mathrm{dCTP},-\mathrm{dGTP},-\mathrm{dATP}$, and $-\mathrm{dTTP}$. The arrowhead indicates primer +1 reaction product.

mixing TLC1 and 476GUG enzyme fractions. Wild-type telomerase was as active in this mixed extract as in extracts from TLC1 cells and TLC1/tIC1-476GUG heterozygous diploid cells, allowing for the different volumes of extracts used (Fig. 6C, cf. lane 4 with lanes 1 and 3). Hence, the lack of telomerase activity in t1c1-476GUG haploids was not attributable to a soluble, trans-acting enzyme inhibitor. In an analagous series of mixing experiments, the mutant 476GUG telomerase, isolated from mutant haploid cells, was assayed specifically. Its activity was not restored by addition of active wild-type telomerase extracted from TLC1 cells (Fig. 6D, lanes 2,4). Hence, the 476GUG template mutant telomerase was functional only when assembled in vivo in the presence of wild-type telomerase.

\section{Discussion}

Here we have shown that $S$. cerevisiae telomerase predominantly polymerizes only a single, often incomplete round of telomere elongation, both in vivo and in vitro. We have confirmed that this nonprocessive, ATP-independent activity is telomerase by demonstrating that mutations in the TLCl templating domain result in compensatory changes in dNTP incorporation by this enzyme in vitro. Three of the trinucleotide substitutions in the TLC1 RNA templating domain also led to novel, unpredicted alterations in specific aspects of telomerase action. These results indicate that the template domain of the TLC1 RNA plays a critical role in catalysis that extends beyond simply providing the template for the addition of telomeric repeats.

\section{TLC1 dependence of S. cerevisiae telomerase activity}

It is clear that the TLC1 gene is required for telomere maintenance in S. cerevisiae, and previous work (Singer and Gottschling 1994) and the work reported here demonstrate that mutations in the TLC1 template region are copied into the telomeric DNA in vivo. Here we have shown directly that the activity we describe copies mutated TLCl RNA templating residues into DNA products in vitro. Furthermore, the 467GUG mutation causes in vitro synthesis to proceed one nucleotide beyond the normal maximal template boundary. These results establish that the activity examined in this study is telomerase.

Recent reports of activities attributed to telomerase in S. cerevisiae cell extracts have differed in their assessments of the ATP dependence (Lue and Wang 1995), processivity, and TLC1 or EST1 dependence of these activities (Cohn and Blackburn 1995; Lin and Zakian 1995; Lue and Wang 1995; Steiner et al. 1996). The activity we describe here is nonprocessive, TLC1 dependent, and both EST1 and ATP independent (Cohn and Blackburn 1995). Although it is possible that different extraction and/or fractionation conditions result in the gain or loss of enzyme activities, fractionation and elution from a number of different ion exchange resins under a variety of ionic concentrations did not alter the processivity or general characteristics of the activity characterized here (J. Prescott and E.H. Blackburn, unpubl.). We suggest that in vitro activities that have been reported as TLC1 independent represent activity or activities other than telomerase. We propose confining the definition of telomerase to the original one of an enzyme dependent on an intrinsic RNA component containing a template domain-the TLC1 RNA in the case of $S$. cerevisiae. These results do not exclude a role for Estlp in S. cerevisiae telomerase 
function in vivo, as suggested by the Est $1^{-}$phenotype (Lundblad and Szostak 1989) and the coimmunoprecipitation of both TLC1 RNA and a telomerase-like activity with Estlp (Steiner et al. 1996).

\section{A nonprocessive telomerase can account for the irregularity of $\mathrm{S}$. cerevisiae telomeric repeats}

This work can explain how a single telomerase ribonucleoprotein (RNP), containing an invariant template domain, can produce degenerate telomeric repeats. We propose that as we have shown in vitro, polymerization by $S$. cerevisiae telomerase in vivo rarely utilizes the entire template domain and thus generates telomeres with varying extreme $3^{\prime}$ termini, which can realign with the partially redundant telomerase RNA template sequence in multiple registers. In characterizing the de novo addition of telomeres in $S$. cerevisiae, Kramer and Haber (1993) found that the first telomeric repeat added was almost always (GT)GTGTGGGTGTG, followed by more degenerate $\mathrm{TG}_{1-3}$ repeats. The $3^{\prime}$ end of this common sequence is exactly that predicted if telomerase frequently stopped synthesis during the addition of the last three templated nucleotides in vivo, as we have shown it to do in vitro. Hence, the activity that we have characterized in this study appears to reflect accurately the in vivo action of $S$. cerevisiae telomerase.

The nonprocessivity of the $S$. cerevisiae telomerase appears to be a property intrinsic to this enzyme, regardless of reaction conditions, enzyme purification level, and primer used. Telomerase from the closely related yeast $S$. castellii was shown previously to catalyze multiple rounds of 8-base telomeric repeat addition under reaction conditions identical to those used for $S$. cerevisiae telomerase, and in vitro mixing experiments showed that $S$. cerevisiae does not contain any diffusable factors that decrease the processivity of the $S$. castellii telomerase (Cohn and Blackburn 1995). In a standard primer extension assay, mouse telomerase activity was found to be nonprocessive in vitro. However, synthesis predominantly extended to a full single round, although it stopped one nucleotide before the $5^{\prime}$ end of the maximal possible RNA template sequence (Prowse et al. 1993; Blasco et al. 1995a). This nonprocessivity was also apparently intrinsic to the enzyme, rather than the result of a trans-acting factor (Prowse et al. 1993). However, a PCR-based assay, which specifically amplifies telomerase products resulting from multiple rounds of elongation, reveals multiple-round primer elongation products (Blasco et al. 1995a; Prowse and Greider 1995).

Telomerase action ensures the replenishment of DNA that is lost from the telomeres during each cell division because of the inherent incomplete replication of linear molecules by DNA polymerase. Conceptually, this could be accomplished either by addition of large amounts of telomeric DNA once every several divisions or addition of small amounts of telomeric DNA with every cell cycle. In clonal $S$. cerevisiae populations, telomere length changes occur in small increments, with maximal length heterogeneity requiring many rounds of DNA replication (Shampay and Blackburn 1988). When mutations that prevent telomere maintenance are introduced into yeast cells, telomeric DNA is lost at a rate of 3-5 bp per cell division (Lundblad and Szostak 1989; Singer and Gottschling 1994). Thus, it is not necessary for telomerase to polymerize long stretches of telomeric DNA to counteract the relatively small losses incurred in its absence. The data presented here indicate that $S$. cerevisiae telomerase acts primarily by polymerizing a short stretch of telomeric DNA. Thus, such synthesis would likely act at every cell cycle. Previous sequence analysis of telomeres synthesized in Tetrahymena cells expressing both wild-type and mutant template telomerases indicated that Tetrahymena telomerase also acts primarily nonprocessively in vivo ( $\mathrm{Yu}$ and Blackburn 1991).

\section{Certain tlc1-GUG template mutations alter enzyme functions}

Here we have demonstrated that GUG trinucleotide substitutions in and adjacent to the template of the $1.3-\mathrm{kb}$ telomerase RNA can have dramatic effects on the enzymatic properties of telomerase. If the templating domain of the RNA simply fed through the catalytic center, providing a template on which protein subunits can align dNTPs for polymerization, such mutations would be predicted only to change the sequence of the reaction products. However, the 472GUG mutation strongly stimulated slippage synthesis under some conditions, and the 467GUG mutation outside the template caused apparent readthrough beyond the normal template. Most unexpectedly, the 476GUG mutation destroyed telomerase activity in the absence of wild-type TLC1 RNA and caused cell senescence. Furthermore, in diploid TLC1/ tlc1-476GUG cells the mutant 476GUG RNA template was copied into mutant telomeric repeats and was copied in vitro in extracts prepared from these cells, despite the 476GUG telomerase from haploid cells being nonfunctional in vivo or in vitro. This requirement for the wild-type TLC1 RNA opens the possibility that two telomerase RNAs may act together to form an active complex. Alternatively, it is possible that this mutant telomerase has lost a component during purification from tIc1-476GUG cells and that this component is stabilized by the presence of wild-type TLC1 RNA.

Unpredicted impairments of telomerase functions have also been found with template region mutations in Tetrahymena telomerase, variously resulting in loss of enzyme fidelity, premature termination of polymerization and dissociation of the elongating product, and readthough beyond the template (Autexier and Greider 1995; Gilley et al. 1995; Gilley and Blackburn 1996). Therefore, we conclude that the TLC1 RNA templating domain also forms an integral part of the telomerase catalytic center, so that disrupting base-specific interactions by altering RNA residues causes highly specific effects on enzyme activity. 
Senescence of tlcl-476GUG cells

The senescence of haploid t1c1-476GUG cells was expected for cells lacking telomerase activity. However, the onset of senescence preceded the telomeres becoming critically short. Thus, strikingly, late passage tlc1472GUG and t1c1-478GUG mutant strains continued to grow comparably to wild type, although their telomeres were considerably shorter than the telomeres of $t l c 1-$ 476 GUG cells at the point of onset of visible senescence. This observation suggests that factors other than short telomeres per se cause tlc1-476GUG cells to senesce. Our data indicate that the senescence of $t 1 c 1-476 G U G$ haploids cannot be attributed solely to loss of Raplp binding to mutant telomeric repeats, as 478GUG and 476GUG mutant repeats were equally impaired for Raplp binding, yet only the tlc1-4676GUG cells senesced. Estlp and Cdcl3p have both been proposed to bind a telomeric $3^{\prime}$ overhang and to recruit telomerase to the telomere (Cohn and Blackburn 1995; Nugent et al. 1996; Steiner et al. 1996). It is therefore possible that an impaired interaction of such an end binding factor in haploid tlc1476 GUG cells contributes to their senescence.

In summary, these results have shown that trinucleotide substitutions in the templating region of the $1.3-\mathrm{kb}$ telomerase RNA can have specific and profound effects on the ability of telomerase to carry out its functions.

\section{Materials and methods}

\section{Strain construction}

All of the yeast strains used in this study were derived from BJ5628 (Jones 1991). Strains containing TLC1 template mutations were made by first subcloning a 1.3-kb Xhol fragment containing the TLC1 gene into the yeast integrating plasmid pRS316. Mutant template fragments ( $309 \mathrm{bp}$ ) were generated by a two step overlap PCR method (Ho et al. 1989) and subcloned into pRS316TLC1 at NcoI-BlpI. PCR-amplified DNAs were sequenced and shown to contain only the intended mutations. One copy of the TLC1 gene was replaced with the various mutant tlc1 genes in standard loop-in/loop-out gene replacement (Rothstein 1991). Their presence and proper location were verified by Southern analysis (Sambrook et al. 1989). Haploids were generated by sporulation, after transforming the parent diploid strains with a plasmid containing $P E P 4$ and $P R B 1$, and analyzed for the presence of either the wild-type or mutant TLC1 gene by Southern analysis (Sambrook et al. 1989).

\section{Cloning and sequencing of de novo telomeres}

TLC1/tlc1 heterozygous diploid strains were transformed with a linearized pRS316-based (Sikorski and Hieter 1989) plasmid containing $108 \mathrm{bp}$ of GT/CA DNA at each end, oriented with the GT strands extending $5^{\prime} \rightarrow 3^{\prime}$ toward the plasmid ends. Transformants were pooled and genomic DNA was isolated by vortexing with glass beads and phenol. DNA was digested with SmaI, treated with T4 DNA polymerase, and recircularized with ligase. E. coli XL1-blue cells (Stratagene) were transformed with the ligation mix, and plasmid DNA was prepared from individual transformants. De novo telomeres were sequenced using Sequenase (U.S. Biochemical), according to the manufacturer's suggestions.

\section{Southern blotting}

Newly sporulated haploid strains were passed in liquid media for up to 85 generations. Genomic DNA was isolated following $25,45,65$, and 85 generations of growth. Approximately $1 \mu \mathrm{g}$ of genomic DNA was digested either with $X$ hoI, or with both XhoI and ApaLI, and subjected to electrophoresis on a $0.8 \%$ agarose gel in TBE for $16 \mathrm{hr}$ at $60 \mathrm{~V}$. The gel was soaked in $0.3 \mathrm{~N} \mathrm{HCl}$ for $15 \mathrm{~min}, 1.5 \mathrm{M} \mathrm{NaCl} / 0.5 \mathrm{~N} \mathrm{NaOH}$ for $15 \mathrm{~min}$, and transferred to Hybond+ nytran membrane (Amersham) in $1.5 \mathrm{M} \mathrm{NaCl} / 0.5 \mathrm{~N}$ $\mathrm{NaOH}$. The membrane was hybridized to the $\gamma^{32} \mathrm{P}$-labeled oligonucleotide (TGTGGG) ${ }_{4}$ at $55^{\circ} \mathrm{C}$ according to Church and Gilbert \{1984\}.

\section{Extract preparation and fractionation}

Whole-cell extracts were prepared essentially as described by Cohn and Blackburn (1995). S-100 supernatants (in TMG buffer: $10 \mathrm{~mm}$ Tris- $\mathrm{HCl}$ at $\mathrm{pH} 8,1.2 \mathrm{mM} \mathrm{MgCl}_{2}, 10 \%$ glycerol, $0.1 \mathrm{~mm}$ EDTA, 0.1 mM EGTA, $1.5 \mathrm{~mm}$ dithiothreitol, $1 \mathrm{mM}$ PMSF, and $1 \mathrm{~mm}$ benzamidine) were adjusted to $0.5 \mathrm{M} \mathrm{NaOAc}$, loaded onto a DEAE-agarose column (Biogel; Bio-Rad) equilibrated in the same buffer, washed with TMG/0.5 $\mathrm{M} \mathrm{NaOAc}$, and eluted with TMG/0.75 M NaOAc. Eluted fractions were desalted and concentrated 8- to 10-fold on Microcon-30 columns (Amicon). When DEAE fractions from the different template mutants were compared to each other, some fractions were diluted with TMG so that all contained equal amounts of telomerase RNA, measured by dot blot analysis. Telomerase fractionated on a cation exchange column was prepared by loading $4 \mathrm{ml}$ of S-100 $(75 \mathrm{mg}$ protein) onto a 5-ml Econo-Pac S cartridge (Bio-Rad) in TMG. The flowthrough was concentrated 8- to 10-fold on Microcon-30 columns (Amicon) and assayed as described below.

\section{Rap1p binding assays}

Twenty-microliter binding reactions contained S-100 wholecell extracts $\{1-2 \mu \mathrm{g}$ of protein $\}, 20$ fmoles $\gamma-{ }^{32} \mathrm{P}$-labeled (C strand-labeled) double-stranded oligonucleotide, 0-60 pmoles of unlabeled double-stranded oligonucleotide, $4 \mathrm{~mm} \mathrm{MgCl}_{2}, 7 \%$ glycerol, $12.5 \mathrm{~mm}$ HEPES (pH 7.8), $125 \mathrm{~mm} \mathrm{NaCl}, 0.25 \%$ Triton $\mathrm{X}-100,1.25 \mathrm{~mm} \mathrm{DTT}$, and $20 \mathrm{ng} / \mathrm{\mu l}$ each of $\mathrm{dI} / \mathrm{dC}$, yeast RNA and sonicated herring sperm DNA. Reactions were incubated for $5 \mathrm{~min}$ at $30^{\circ} \mathrm{C}$, loaded directly onto a native $6 \%$ acrylamide (80:1) gel, and run at $120 \mathrm{~V}$ for $90 \mathrm{~min}$ in TBE buffer.

\section{In vitro telomerase reactions}

Unless indicated otherwise, telomerase reactions contained $50 \%$ (vol/vol) DEAE fraction, $50 \mathrm{mM}$ Tris- $\mathrm{HCl}(\mathrm{pH} \mathrm{8}), 1 \mathrm{~mm}$ spermidine, 1 mM DTT, $50 \mu \mathrm{M}$ dGTP, $50 \mu \mathrm{M}$ dATP, $50 \mu \mathrm{M} \mathrm{dCTP}$, $7.5 \mu \mathrm{M}\left[\alpha_{-}{ }^{32} \mathrm{P}\right] \mathrm{dTTP}(400 \mathrm{Ci} / \mathrm{mmole})$, and $1 \mu \mathrm{M}$ primer. Standard $20-\mu \mathrm{l}$ reactions were incubated at $30^{\circ} \mathrm{C}$ for $30 \mathrm{~min}$, stopped with the addition of $2.5 \mu \mathrm{l}$ of stop buffer ( $2 \%$ SDS, $250 \mathrm{~mm}$ Tris- $\mathrm{HCl}$ at $\mathrm{pH} 8,250 \mathrm{~mm}$ EDTA $)$ and $2.5 \mu \mathrm{l}$ of proteinase $\mathrm{K}(20 \mathrm{mg} / \mathrm{ml})$, and incubated at $65^{\circ} \mathrm{C}$ for $25 \mathrm{~min}$. Reactions were extracted with phenol $/ \mathrm{CHCl}_{3} /$ isoamyl alcohol $(25: 24: 1)$ and precipitated with 2.5 volumes of ethanol. Reaction products were resolved on $15 \%$ acrylamide/ $8 \mathrm{M}$ urea gels and visualized by autoradiography. RNase pretreatment of DEAE fractions consisted of a 5 -min incubation at $30^{\circ} \mathrm{C}$ with $10 \mu \mathrm{g} / \mathrm{ml}$ of RNase A immediately prior to the addition of primer and nucleotides.

\section{Acknowledgments}

We thank Dan Gottschling for the TLC1 gene, Elizabeth Jones for PEPA and PRB1 genes, and Corrie Detweiler for tetrad dis- 
section instruction; Anat Krauskopf, Karen Kirk, Anamitra Bhattacharyya, Mike McEachern, Tracy Boswell Fulton, and Chris Smith for critical reading of the manuscript; and Anat Krauskopf, Jagoree Roy, Tracy Boswell Fulton, and Mike McEachern for helpful discussions. This research was supported by grant GM26259 from the National Institutes of Health (to E.H.B.). J.P. was supported by a postdoctoral fellowship from the Damon Runyon-Walter Winchell Cancer Fund.

The publication costs of this article were defrayed in part by payment of page charges. This article must therefore be hereby marked "advertisement" in accordance with 18 USC section 1734 solely to indicate this fact.

\section{References}

Autexier, C. and C.W. Greider. 1995. Boundary elements of the Tetrahymena telomerase RNA template and alignment domains. Genes \& Dev. 9: 2227-2239.

Blackburn, E.H. 1994. Telomeres-No end in sight. Cell 77: 621-623.

Blasco, M.A., W. Funk, B. Villeponteau, and C.W. Greider. 1995a. Functional characterization and developmental regulation of mouse telomerase RNA. Science 269: 1267-1270.

Blasco, M.A., M. Rizen, C.W. Greider, and D. Hanahan. 1995b. Differential regulation of telomerase activity and telomerase RNA during multi-stage tumorigenesis. Nature Genet. 12: $200-204$

Chikashige, Y., D.Q. Ding, H. Funabiki, T. Haraguchi, S. Mashiko, M. Yanagida, and Y. Hiraoka. 1994. Telomere-led premeiotic chromosome movement in fission yeast. Science 264: 270-273.

Church, G.M. and W. Gilbert. 1984. Genomic sequencing. Proc. Natl. Acad. Sci. 81: 1991-1995.

Cohn, M. and E.H. Blackburn. 1995. Telomerase in yeast. Science 269: 396-400.

Collins, K. and C.W. Greider. 1993. Tetrahymena telomerase catalyzes nucleolytic cleavage and nonprocessive elongation. Genes \& Dev. 7: 1364-1376.

Dernburg, A.F., J.W. Sedat, W.Z. Cande, and H.W. Bass. 1995. Cytology of telomeres. In Telomeres (ed. E. Blackburn and C. Greider), pp. 295-338. Cold Spring Harbor Laboratory Press, Cold Spring Harbor, NY.

Feng, J., W.D. Funk, S.-S. Wang, S.L. Weinrich, A.A. Avilion, C.-P. Chiu, R.R. Adams, E. Chang, R.C. Allsopp, I. Yu, S. Le, M.D. West, C.B. Harley, W.H. Andrews, C.W. Greider, and B. Villeponteau. 1995. The RNA component of human telomerase. Science 269: 1236-1240.

Gilley, D. and E.H. Blackburn. 1996. Specific RNA residue interactions required for enzymatic functions of Tetrahymena telomerase. Mol. Cell. Biol. 16: 66-75.

Gilley, D., M.S. Lee, and E.H. Blackburn. 1995. Altering specific telomerase RNA template residues affects active site function. Genes \& Dev. 9: 2214-2226.

Greider, C.W. 1996. Telomere length regulation. Annu. Rev. Biochem. 65: 337-365.

Greider, C.W. and E.H. Blackburn. 1985. Identification of a specific telomere terminal transferase activity in Tetrahymena extracts. Cell 43: 405-413.

-1989. A telomeric sequence in the RNA of Tetrahymena telomerase required for telomere repeat synthesis. Nature 337: 331-337.

Henderson, E.R. and E.H. Blackburn. 1989. An overhanging $3^{\prime}$ terminus is a conserved feature of telomeres. Mol. Cell. Biol. 9: 345-348.

Ho, S.N., H.D. Hunt, R.M. Horton, J.K. Pullen, and L.R. Pease.
1989. Site-directed mutagenesis by overlap extension using the polymerase chain reaction. Gene 77: 51-59.

Jones, E. 1991. Tackling the protease problem in Saccharomyces cerevisiae. Methods Enzymol. 194: 428-453.

Klobutcher, L.A., M.T. Swanton, P. Donini, and D.M. Prescott. 1981. All gene-sized DNA molecules in four species of hypotrichs have the same terminal sequence and an unusual $3^{\prime}$ terminus. Proc. Nat1. Acad. Sci. 78: 3015-3019.

Kohli, J. 1994. Telomeres lead chromosome movement. Curr. Biol. 4: 724-727.

Kramer, K.M. and J.E. Haber. 1993. New telomeres in yeast are initiated with a highly selected subset of $\mathrm{TG}_{1-3}$ repeats. Genes \& Dev. 7: 2345-2356.

Krauskopf, A. and E.H. Blackburn. 1996. Control of telomere growth by interactions of RAP1 with the most distal telomeric repeats. Nature 383: 354-357.

Lin, J.-J. and V.A. Zakian. 1995. An in vitro assay for Saccharomyces telomerase requires EST-1. Cell 81: 1127-1135.

Lingner, J., L.L. Hendrick, and T.R. Cech. 1994. Telomerase RNAs of different ciliates have a common secondary structure and a permuted template. Genes \& Dev. 8: 1984-1998.

Lue, N.P. and J.C. Wang. 1995. ATP-dependent processivity of a telomerase activity from Saccharomyces cerevisiae. J. Biol. Chem. 270: 21453-21456.

Lundblad, V. and J.W. Szostak. 1989. A mutant with a defect in telomere elongation leads to senescence in yeast. Cell 57: 633-643.

Lindblad, V. and E.H. Blackburn. 1993. An alternative pathway for yeast telomere maintenance rescues est1- senescence. Cell 73: 347-360.

Lustig, A.J. 1992. Hoogsteen G-G base pairing is dispensable for telomere healing in yeast. Nucleic Acids Res. 20: 3021-3028.

McEachern, M.J. and E.H. Blackburn. 1994. A conserved sequence motif within the exceptionally diverse telomeric sequenced of budding yeasts. Proc. Natl. Acad. Sci. 91: 34533457.

-1995. Runaway telomere elongation caused by telomerase RNA gene mutations. Nature 376: 403-409.

Melek, M., E.C. Greene, and D.E. Shippen. 1996. Processing of nontelomeric 3 ' ends by telomerase: Default template alignment and endonucleolytic cleavage. Mol. Cell. Biol. 16: $3437-3445$.

Nugent, C.I., T.R. Hughes, N.F. Lue, and V.I. Lundblad. 1996. Cdc13p: A single-strand telomeric DNA-binding protein with a dual role in yeast telomere maintenance. Science 274: 249-252.

Olovnikov, A.M. 1973. A theory of marginotomy. J. Theor, Biol. 41: $181-190$.

Prowse, K.R. and C.W. Greider. 1995. Developmental and tissue specific regulation of mouse telomerase and telomere length. Proc. Nat1. Acad. Sci.92: 4818-4822.

Prowse, K.R., A.A. Avilion, and C.W. Greider. 1993. Identification of a nonprocessive telomerase activity from mouse cells. Proc. Nat1. Acad. Sci. 90: 1493-1497.

Romero, D. and E.H. Blackburn. 1991. A conserved secondary structure for telomerase RNA. Cell 67: 343-353.

Rothstein, R. 1991. Targeting, disruption, replacement, and allele rescue: Integrative DNA transformation in yeast. Methods Enzymol. 194: 281-301.

Sambrook, J., E.F. Fritsch, and T. Maniatis. 1989. Molecular cloning: A laboratory manual, 2nd edition. Cold Spring Harbor Laboratory Press, Cold Spring Harbor, NY.

Shampay, J. and E.H. Blackburn. 1988. Generation of telomerelength heterogeneity in Saccharomyces cerevisiae. Proc. Natl. Acad. Sci. 85: 534-538. 
Shampay, J., J.W. Szostak, and E.H. Blackburn. 1984. DNA sequences of telomeres maintained in yeast. Nature 310: 154 157.

Sikorski, R.S. and P. Hieter. 1989. A system of shuttle vectors and yeast host strains designed for efficient manipulation of DNA in Saccharomyces cerevisiae. Genetics 122: 19-27.

Singer, M.S. and D.E. Gottschling. 1994. TLC1-Template RNA component of Saccharomyces cerevisiae telomerase. Science 266: 404-409.

Steiner, B.R., K. Hidaka, and B. Futcher. 1996. Association of the Estl protein with telomerase activity in yeast. Proc. Natl. Acad. Sci. 93: 2817-2821.

Szostak, J.W. and E.H. Blackburn. 1982. Cloning yeast telomeres on linear plasmid vectors. Cell 29: 245-255.

Watson, J.D. 1972. Origin of concatameric T7 DNA. Nature New Biol. 239: 197--201.

Wellinger, R.J., A.J. Wolf, and V.A. Zakian. 1993. Saccharomyces telomeres acquire single-strand $\mathrm{TG}_{\{1-3\}}$ tails late in $S$ phase. Cell 72: 51-60.

Yu, G.-L. and E.H. Blackburn. 1991. Developmentally programmed healing of chromosomes by telomerase in Tetrahymena. Cell 67: 823-832.

Yu, G.-L., J.D. Bradley, L.D. Attardi, and E.H. Blackburn. 1990. In vivo alteration of telomere sequences and senescence caused by mutated Tetrahymena telomerase RNAs. Nature 344: 126-132.

Zakian, V.A. 1995. Telomeres: Beginning to understand the end. Science 270: 1601-1607. 


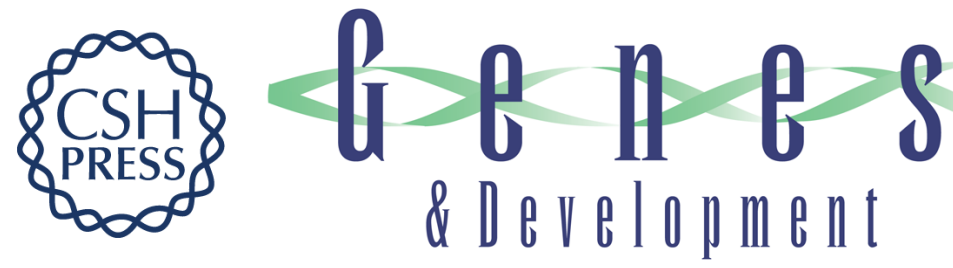

\section{Telomerase RNA mutations in Saccharomyces cerevisiae alter telomerase action and reveal nonprocessivity in vivo and in vitro.}

$\mathrm{J}$ Prescott and E H Blackburn

Genes Dev. 1997, 11:

Access the most recent version at doi:10.1101/gad.11.4.528

References This article cites 47 articles, 24 of which can be accessed free at: http://genesdev.cshlp.org/content/11/4/528.full.html\#ref-list-1

License

Email Alerting Service right corner of the article or click here.

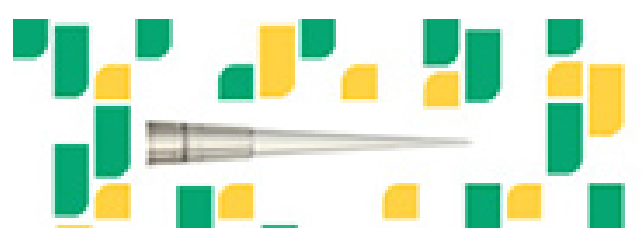

Focused on your science. 